\title{
O JOGO SEMÂNTICO DO VERBO LLEVAR: UMA ANÁLISE DE MANCHETES DE SITES EM LÍNGUA ESPANHOLA
}

\author{
EL JUEGO SEMÁNTICO DEL VERBO LLEVAR: ANÁLISIS DE SITIOS EN LENGUA \\ ESPAÑOLA
}

\author{
THE SEMANTIC GAME OF THE VERB LLEVAR: AN ANALYSIS OF SPANISH \\ LANGUAGE SITES HEADLINES
}

Ana Maria BONK MASSAROLLO ${ }^{1}$

RESUMO: Este trabalho tem por objetivo discutir as categorias semânticas do verbo llevar a partir de frases retiradas de jornais eletrônicos. Apresentados com diferentes sentidos, as frases destacadas para a análise deste trabalho apresentam sentidos metafóricos com significados diferentes para distintos contextos. Para tanto, os textos foram analisados fundamentando-se na aplicação das categorias semânticas cultural, gramatical e conceitual, segundo a abordagem de Moura (2006) e Lakoff e Johnson (1980; 2002). Ao final do estudo, percebeu-se que as variações semânticas decorrentes da utilização do verbo llevar variam de acordo com o contexto de uso, bem como os sentidos possibilitados nas construções sintáticas ultrapassam um nível superficial de compreensão do interlocutor: a polissemia do verbo e o contexto de seu proferimento interferem na sua realização e nos sentidos proferidos.

PALAVRAS-CHAVE: Semântica. Verbo llevar. Metáfora e metonímia.

RESUMEN: Este trabajo tiene como objetivo discutir las categorías semánticas del verbo llevar a partir de frases extraídas de periódicos electrónicos. Presentadas con diferentes significados, las frases destacadas para el análisis de este trabajo presentan significados metafóricos con diferentes significados para diferentes contextos. Para ello, los textos fueron analizados a partir de la aplicación de categorías semánticas culturales, gramaticales y conceptuales, según el enfoque de Moura (2006) y Lakoff y Johnson (1980; 2002). Al final del estudio, se observó que las variaciones semánticas resultantes del uso del verbo llevar varían según el contexto de uso, así como los significados posibilitados en las construcciones sintácticas van más allá de un nivel superficial de comprensión del interlocutor: la polisemia del verbo y la el contexto de su enunciado interfiere en su realización y en los significados enunciados.

PALABRAS CLAVE: Semántica. Verbo llevar. Metáfora y metonimia.

ABSTRACT: This paper aims to discuss the semantic categories of the verb llevar from sentences taken from electronic newspapers. Presented with different meanings, the sentences highlighted for the analysis of this work present metaphorical meanings with different meanings for different contexts. Therefore, the texts were analyzed based on the application of the

${ }^{1}$ Instituto Federal de Santa Catarina (IFSC), Chapecó - SC - Brasil. Professora de espanhol. Doutoranda em Linguística (UFSC). ORCID: https://orcid.org/0000-0003-1081-4211. E-mail: ana.bonk@ifsc.edu.br 
cultural, grammatical and conceptual semantic categories, according to the approach of Moura (2006) and Lakoff and Johnson (1980; 2002). At the end of the study, it was noticed that the semantic variations resulting from the use of the llevar verb vary according to the context of use, as well as the meanings made possible in syntactic constructions surpass a superficial level of understanding of the interlocutor: the verb polysemy and the context of its utterance interfere with its accomplishment and the senses uttered.

KEYWORDS: Semantics. Llevar verb. Metaphor and metonymy.

\section{Introdução}

Por meio da semântica é possível atribuirmos significados às sentenças ditas ou escritas. De acordo com as pesquisas realizadas pelos estudos linguísticos frente ao estudo do significado, ou seja, da semântica propriamente dita, podemos situar as reflexões a partir das pesquisas filosóficas e da linguagem ao longo dos últimos cem anos. Primeiramente, pode-se observar que a semântica "[...] não descende da linguística estruturalista saussureana [...], mas da tradição da lógica e da filosofia da linguagem, de cunho analítico.” (BASSO, 2009, p. 10). É nesse espaço que, por muito tempo, a semântica era estudada primordialmente por filósofos: tratava-se de um espaço voltado às reflexões sobre lógica linguagem e matemática (BASSO, 2009).

No Brasil, é a partir da década de 70 que o cunho filosófico se transpõe para a ótica linguística, mas sem deixá-lo de lado, já que a semântica nada pode dizer sobre o significado da vida enquanto tal ou de qualquer outra "coisa" no mundo, porque ela explica apenas um tipo muito específico de fenômeno: o significado que atribuímos às sentenças e expressões de uma língua natural, uma língua que aprendemos no berço, sem aprendizagem formal.

Nesse construto, não basta separar o significado linguístico do significado nãolinguístico para delimitar o campo da semântica, porque o estudo do significado linguístico transborda tais premissas: às margens da semântica, os estudos ocupam também a pauta das ciências cognitivas e, em particular, da Pragmática. Para tanto, se faz necessário observar a noção de significado linguístico, que pode ser subdividido em dois níveis: um que está atrelado ao significado da sentença; e outro, que depende do significado da sentença e de mais informações sobre a situação em que a sentença é proferida pelo falante. Pode-se dizer, então, que a semântica analisa o significado da sentença, sem levar em consideração a intenção do falante.

É nesse espaço teórico que este artigo apresenta a análise de manchetes retiradas de sites em língua espanhola, levando em consideração algumas contribuições da semântica 
argumentativa, pois entende-se a relevância de se considerar o significado relacional entre locutor e interlocutor. Em consonância com Moura (2014, p. 36), “[...] as palavras servem de premissas para conclusões, na sequência do discurso. Um enunciado não descreve o mundo, ele aponta para certas conclusões sobre o estado de coisas". Dessa forma, importa para a semântica argumentativa o encadeamento discursivo, ou seja, os enunciados têm significado dentro da cadeia discursiva e revelam uma forma de pensar o mundo.

A fim de elucidar o recém-exposto, de início, este artigo apresenta reflexões acerca da semântica e da polissemia com base nos pressupostos teóricos de Moura (2006). Por conseguinte, são retratadas teoricamente metáfora e metonímia, à luz de Carvalho (s/d) e Jakoff e Johnson (1980). A etapa analítica das manchetes comporta a sequência deste estudo que, por fim, traz nas considerações finais apontamentos reflexivos acerca da temática aqui alavancada.

\section{A semântica e polissemia: reflexões acerca do contexto e do uso}

Segundo as bases da semântica argumentativa, cada palavra tem um potencial argumentativo que pode ser apreendido através de inferências. Assim ela também considera as possibilidades que a linguagem humana apresenta em termos de orientar o discurso a partir das potencialidades que o sentido conotativo possibilita, portanto importa o sentido linguístico que se produz no discurso, na língua em uso.

A partir do exposto, ainda de acordo com Moura (2006), a palavra isolada é estéril, mas quando contextualizada revela uma infinita possibilidade polissêmica, portanto o contexto é de fundamental relevância para apontar o sentido e para que a sentença seja interpretável. A interpretação vai depender de cada locutor e interlocutor, de acordo com os conhecimentos compartilhados e da capacidade de interação e apreensão do sentido intencionado, logo, se faz importante observar o contexto de cada situação comunicativa.

O contexto pode ser considerado o campo de intersecção entre a pragmática e a semântica argumentativa. Ao mencionar a importância do contexto, salienta-se que os enunciados apresentados neste artigo dependem de uma recuperação anafórica por parte do público ao qual se dirigem, já que há um conhecimento compartilhado entre os participantes da interação, bem como informações complementares que são resgatadas e que tornam viável a atribuição de novos sentidos e usos para uma palavra qualquer, desde que contextualizada explícita ou implicitamente.

Moura (2006) diz que os limites puramente semânticos não nos permitem determinar os limites referenciais, e por esta razão o contexto se faz necessário para a recuperação do sentido 
pretendido. Este emprego no caso do verbo llevar, o que motiva o interlocutor a empregá-lo, diz respeito às crenças assumidas pelo sujeito enunciador, uma vez que este imagina que os interlocutores para os quais ele se dirige compartilham conhecimentos necessários que garantem a compreensão e apreensão do sentido dado pelo interlocutor. É por esse viés que semântica e pragmática dialogam, pois é o contexto que determinará a variação polissêmica da palavra:

A pragmática envolve a atribuição de certas crenças ao interlocutor, que delimitam o contexto da interpretação. Os contextos que não dependem dessa atribuição de crenças, não são pragmáticos, mas definidos no componente semântico, em função da dinâmica do discurso (MOURA, 2006, p. 76).

Uma vez definidos os conceitos de semântica e seus entornos, que se entrelaçam e permeiam este estudo, se faz necessário afirmar que não são apenas esses construtos teóricos que sustentam o uso do verbo llevar, em destaque na parte analítica deste estudo. Junta-se a eles o uso constante das figuras de linguagem metáfora e metonímia, apontadas a seguir.

\section{Metáfora e metonímia: o uso permeado pelo contexto}

O vocábulo metáfora tem origem no grego $($ meta $=$ trans + phérein $=$ levar $)$ e "[...] significa mudança, transferência, transposição; no caso específico do fenômeno semântico, a mudança seria de um sentido próprio para um outro, figurado" (CARVALHO, s/d, p. 17).

Para Pollio et al. (1990), à luz de Carvalho (s/d, p. 2), o processo de construção da metáfora, já que há mudança de sentidos quanto ao uso dos vocábulos em determinado contexto, “[...] parece se dar na tentativa de fazer o mundo abstrato compreensível ou em trazer o mundo para dentro de nós mesmos ou de irmos até ele". Nesse sentido, a metáfora tem como função ir para além das capacidades comunicativas e de conceitualização que o ser humano faz: trata-se de uma "janela" para os sistemas de conhecimento e cultura de determinado povo (CARVALHO, s/d).

Por esse viés, Cacciari (1998) afirma que o ser humano, ao pensar em proferir uma sentença, tem a sua disposição várias escolhas, entre elas a forma que ele deseja se expressar: literalmente, ironicamente, metaforicamente, entre outras. Trata-se, portanto, de utilizar a linguagem a favor da comunicação de acordo com o contexto em que se encontra.

A partir do exposto, a metáfora não pode ser tratada apenas como uma figura de linguagem de simples cunho comunicativo. Segundo Lakoff e Johnson (1980), é possível compreender a metáfora a partir do que compreendemos do mundo e da forma como agimos 
nele, ou seja, pela ótica de que a metáfora se materializa verbalmente pelo falante de uma língua, logo, a metáfora é estruturada no pensamento humano.

Além disso, Lakoff e Johnson (1980), em sua obra, destacam inicialmente três tipos de metáforas a partir de Categorias Semânticas: estruturais, orientacionais e ontológicas. As estruturais são aquelas responsáveis por estruturar metafórica e parcialmente um conceito em termos de outro, isto é, quando um determinado elemento é compreendido em função de outro (SILVA, 2018). Como exemplo, Silva (2018) aponta para a estrutura "VIVER É LUTAR" sendo que, segundo o autor,

[...] o mundo existencial (VIVER) se conjuga com o bélico (LUTA), e aqueles que metaforizam o mundo desse jeito verão a vida como uma constante guerra. Enunciados do tipo: hoje meu dia foi uma batalha; tenho que matar um leão por dia; estou pronto para guerra da vida; usarei todas as minhas armas, etc. serão comuns no discurso dos usuários que entendem a vida dessa maneira (SILVA, 2018, p. 121).

Já as metáforas orientacionais indicam espacialidade. Como exemplo, temos expressões como "passar por cima de tudo", "estar parado no meio do caminho" e "estar por baixo" (SILVA, 2018). Uma terceira variedade de metáfora apresentada pelos autores é a chamada metáfora ontológica, também chamada de metáfora que se reduz à personificação: nas palavras de Silva (2018, p. 121), "Maria é uma flor" - como um processo de ontologização da beleza de Maria - e "A noite é uma criança" - como um processo de ontologização da possibilidade de ter tempo para poder se divertir, e brincar, e rir, e sonhar, e imaginar exemplificam esse tipo de metáfora.

Lakoff e Johnson (1980) apontam ainda para o fato de o ser humano ser uma entidade limitada por uma superfície, uma entidade discreta. Nesse espaço de reflexão, os autores afirmam ainda que nossa compreensão acerca de nós mesmos como entidades discretas nos permite impor limites artificiais onde não há contornos bem definidos. Além disso, a metáfora é uma característica restrita à linguagem que está infiltrada na vida cotidiana, no pensamento e na ação, e o que permite que ela seja compreendida é o fato de que nós temos um sistema conceitual que torna viável o uso da metáfora no cotidiano da comunicação humana (LAKOFF; JOHNSON, 1980).

Em sua discussão sobre a metáfora, Lakoff e Johnson mencionam que "nenhuma metáfora pode ser compreendida ou até mesmo representada de forma adequada, independente de sua base experiencial" (2002, p. 69), desta forma a metáfora se baseia na experiência humana, fato que assegura sua compreensão. Os autores também argumentam que os valores 
culturais profundamente enraizados na cultura são compatíveis com os sistemas metafóricos que nela existem (LAKOFF; JOHNSON, 2002).

Em contrapartida aos pressupostos teóricos que descrevem a metáfora está o olhar para a metonímia: por um viés comparativo não se pode afirmar as mesmas premissas da primeira frente a segunda, já que a metáfora, geralmente, aparece como pano de fundo para determinadas situações. Já a metonímia, como se pode observar em Ullmann (1970), se apresenta como recurso estilístico que dispõe de um interesse limitado ao estilo, uma vez que ela surge apenas entre as palavras, além de não revelar relações novas entre os termos.

Nesse sentido, alguns autores afirmam que o emissor e o receptor facilmente percebem a metáfora como um desvio linguístico e que a metonímia, por sua vez, é mais sorrateira, dissimulada e passa despercebida, detectável apenas pela análise linguística. Abrahão (2008) compreende a metonímia sob a perspectiva da Produção de Sentidos com destaque para a importância dos processos histórico-sociais e culturais que sustentam a significação da metonímia para além de uma questão de estilo. Põe-se em relevo também a influência da experiência física na representação de processos de significação fomentados pela metonímia.

Em consonância, Moisés (2004) declara que a delimitação da metonímia à esfera dos nomes é equivocada, isto é, a metonímia não é uma mera relação entre nomes. Em outras palavras, a definição de metonímia, considerada apenas como o uso do nome de uma coisa por outra com a qual está associada, oferece apenas uma visão geral de sua essência.

Nota-se, a partir do exposto, que há em gramáticas tradicionais uma visão restrita acerca das características da metonímia, pois essa visão não ultrapassa a substituição de palavras entre si. Barros (1985), por exemplo, registra que a metonímia consiste na troca de palavras, isto é, emprega-se uma palavra por outra, e a primeira lembra a segunda, que fora omitida. Segundo o autor, a metonímia revela íntima relação entre o significado que se deseja transmitir e o significante usado para expressá-lo.

Já para Câmara Júnior (1968), a metonímia é um processo sincrônico pelo qual se multiplicam as ocasiões de emprego de uma palavra, além do seu campo semântico específico. A metonímia, então, “[...] coloca uma palavra num campo semântico que não é o seu, na base de agrupamentos onomasiológicos das coisas extralinguísticas que não coincidem com os agrupamentos semânticos das formas linguísticas" (CÂMARA JÚNIOR, 1968, p. 239).

Observados tais elementos que cercam o conceito de metáfora e metonímia, embora que de forma breve, pode-se relacioná-los diretamente ao objeto de análise deste artigo: o verbo llevar, de uso na língua espanhola, abrange sentidos para além do sentido denotativo de deslocamento. É pelo olhar da semântica argumentativa que o uso do verbo llevar adquire 
importância argumentativa dentro do enunciado em que se apresenta e que o sentido que carrega em cada recorte selecionado não precisa estar atrelado ao significado lexical previsto restritamente pelo dicionário. Entra em cena o caráter polissêmico da linguagem e seu uso, o qual se desdobra em tantos sentidos devido ao caráter criativo da linguagem, fato que nos permite afirmar que não é possível esgotar ou restringir os sentidos a ele atribuídos nas mais diversas situações de uso, mas sim, há a potencialidade de novos contextos proporcionarem novos significados. Assim, o olhar para o verbo é permeado por uma visão semântica que dialoga com a pragmática, uma vez que as fronteiras destas duas são fluídas (MOURA, 2006).

É necessário destacar que o conhecimento compartilhado culturalmente é um dos fatores que contribui para a eficiência da metáfora nas situações de comunicação: a eficácia na compreensão de uma metáfora implica na sua compreensão dentro da esfera cultural dos interlocutores envolvidos e não necessariamente outros grupos. Como exemplo, tem-se esses elementos empregados nas manchetes aqui analisadas e apresentadas na seção seguinte, que, com o verbo em destaque, trata de frases chamativas a determinado público específico e partese do pressuposto de que os leitores para os quais se destina o texto compartilham suficientes elementos culturais que lhes permitem compreender o sentido pretendido.

\section{O verbo llevar em manchetes de sites em língua espanhola: uma breve análise de uso}

Segundo o Gran Diccionario de la Lengua Española Larousse, o verbo llevar apresenta trinta e sete entradas, o que significa que ele pode ser empregado de diferentes maneiras, com diferentes significados ${ }^{2}$. A partir dessa gama de possibilidades de proferimento e uso do verbo, tendo em vista o caráter polissêmico da linguagem, é possível que estas trinta e sete diferentes possibilidades não esgotem os sentidos atribuídos ao verbo llevar.

Nesse contexto, o presente estudo possibilita a observação e análise de manchetes de sites da internet, em língua espanhola, de modo a recortar algumas situações de uso, com análise à luz das teorias de Moura (2006), de forma a salientar algumas nuances de sentidos atribuídos a este verbo da língua espanhola:

Num primeiro nível, temos informações num plano literal, ou seja, contidas no próprio sentido das palavras [...] num segundo nível, somos levados a considerar, pela simples enunciação de cada [...] sentença, outras informações que não são afirmadas literalmente, mas inferidas a partir [de tais] [...] sentenças (MOURA, 2006, p. 12-13).

${ }^{2}$ Disponível em: http://es.thefreedictionary.com/llevar. Acesso em: 19 jul. 2019. 
Ao nos debruçarmos sobre o verbo llevar à luz da semântica argumentativa, pretendemos discutir as relações de sentido para além do significado lexical que a palavra possa abrigar, pretendendo analisar as situações de uso e as intenções argumentativas que se inscrevem no verbo em questão, pois importa a argumentação que se faz a partir dos sentidos atribuídos ao verbo.

Para tanto, a fim de elucidar tal problemática, selecionamos seis manchetes veiculadas em sites de notícias e entretenimento na internet entre os anos 2013 e 2017. As manchetes, que serão apresentadas a seguir, foram eleitas a partir do critério metafórico em que llevar é empregado, ou seja, além do uso do verbo llevar em sua construção sintática, embora sejam utilizadas de maneira possível pelo nível da sintaxe, é pelo olhar para o viés semântico - que propõe sentidos ao interlocutor - que as manchetes foram escolhidas.

A primeira manchete apresentada e analisada (Figura 1), a partir do construto teórico recém-exposto, foi publicada em dezembro de 2013, em um blog chamado de \#Bernatcoll, que trata assuntos gerais sobre o mundo espanhol:

Figura 1 - Manchete 1

\section{España lleva bigote y conduce un 600. Catalunya lleva minifalda y se siente bien}

Fonte: Bernatcoll (2013) $)^{3}$

A manchete apresentada, "España lleva bigote", na sentença acima, faz referência à ideia de adição de vantagem sobre a Catalunha com imposição de poder, de força, de dominação, observadas principalmente pelo uso de contextos masculino e feminino (bigote e minifalda): trata-se de uma forte relação de gênero na qual percebemos que bigote - em português, bigode -, expressa uma conotação relacionada à masculinidade, em contrapartida à minifalda (em português, minissaia) associada à feminilidade.

Sabe-se que, historicamente, Espanha e Catalunha possuem uma discórdia política e geográfica, uma vez que a comunidade autônoma da Catalunha busca independência do país. Nesse caso, o sentido metafórico de España lleva bigote, na manchete exposta, através de uma metáfora ontológica, remete a interpretações ideológicas de gênero: acerca do lado masculino de um relacionamento, com um olhar preconceituoso e machista; já Catalunha propõe um viés

${ }^{3}$ Disponível em: https://fcbarcelonaroom.wordpress.com/2013/12/12/espana-lleva-bigote-y-conduce-un600-catalunya-lleva-minifalda-y-se-siente-bien/. Acesso em: 20 jul. 2020. 
feminino, o sexo frágil. Historicamente o termo bigote foi atribuído como um símbolo de masculinidade, assim como a minissaia à visão de liberdade, modernidade feminina, de ousadia e, também, muitas vezes relacionada à vulgaridade e ao preconceito com a vestimenta. Assim como a mulher se sente autossuficiente, como nos movimentos feministas em que buscavam espaço de liberdade e autonomia, Catalunha se sente autossuficiente. Neste caso exposto do verbo "llevar", segundo Lakoff e Johnson (1980), está relacionado à categoria semântica estrutural, quando um determinado elemento é compreendido em função de outro. Aqui, tanto a mulher, por esse olhar analítico, quanto a Comunidade Autônoma de Catalunha, encontram na independência o sentimento de satisfação, expresso na manchete como se siente bien.

Em um contraste com a Língua Portuguesa, o modo como o verbo llevar foi empregado tem o mesmo sentido gramatical do verbo "usar" do português. Observa-se nessa sentença, além do exposto, a ocorrência do verbo empregado com sentido metafórico: é o contexto que determina o sentido do verbo que, nesse caso, em España lleva bigote, o verbo não é empregado para afirmar que uma pessoa - nesse caso o país Espanha - usa bigode, de fato. O enunciado em destaque aponta o uso do verbo llevar para determinar questões de gênero, força, poder, estereótipo masculino/feminino, a dominação ou supremacia do país sobre a Comunidade Autônoma de Catalunha, além da histórica divergência entre dois grupos que defendem diferentes interesses nacionalistas: espanhóis que defendem a atual configuração do país e os catalães que almejam uma nova configuração geopolítica com a separação da sua comunidade autônoma da Espanha.

O sujeito enunciador, ao empregar o verbo llevar, conta com a capacidade do seu interlocutor de preencher e apreender o significado metafórico intencionado - bigote com sentido de poder e masculinidade. Nesse caso, a metáfora só tem sentido quando, na situação de comunicação, os falantes conseguem atribuir tal significado.

Em contrapartida à manchete exposta está a segunda manchete selecionada para análise: retirada do site de notícias e entretenimento ABC e publicada em agosto de 2016, ela possui outro viés interpretativo (Figura 2):

Figura 2 - Manchete 2

\section{El hombre que lleva 46 años sin afeitarse el bigote}

Fonte: Abc El Recreo (2016)

${ }^{4}$ Disponível em: https://www.abc.es/recreo/abci-hombre-lleva-46-anos-sin-afeitarse-bigote201608191107_noticia.html. Acesso em: 20 jul. 2020. 
Nesse enunciado, o verbo llevar, segundo Lakoff e Johnson (1980), se apresenta como uma metáfora cronológica e orientacional que indicam tempo e espaço, indicando sentidos de que o tempo decorrido por usar bigode: 46 anos sem aparar ou remover a barba. No contexto semântico, observa-se que um primeiro significado está atrelado à sentença, a uma composição estrita do significado das palavras, e outro, que depende do significado da sentença e mais informações sobre a situação em que a sentença é proferida pelo falante, a qual nos submete a imaginar o tamanho desta barba, a higiene deste bigode ou como faz para se alimentar com um bigode tão extenso e com 46 anos.

Essas possíveis interpretações possibilitam ao leitor a criação de imagens que ultrapassam as restrições da palavra escrita e de um sentido único e de cunho denotativo. $\mathrm{O}$ sentido polissêmico do verbo llevar, nesse caso, é possibilitado por um viés cultural, como apontado por Moura (2006): pode ter-se determinada interpretação já que, para alguns públicos, é comum e cultural o homem aparar a barba constantemente, bem como sinaliza higiene e cuidado consigo mesmo. Da mesma forma, existem culturas em que o uso de bigode e barba elucidam masculinidade e, dessa forma, ter um bigode extenso não causa estranheza.

Além do exposto, é válido elucidar que o verbo llevar poderia ser substituído, em um contraste com a língua portuguesa, pelo verbo "usar" e, também, pelo verbo "estar" junto ao verbo "haver": "O homem que está há 46 anos sem tirar o bigode".

O leque de possibilidades contrastivas quanto ao uso do verbo llevar também está expresso na manchete a seguir (Figura 3), também retirada do site $\mathrm{ABC}$, mas relacionada à moda, com publicação de 2017:

Figura 3 - Manchete 3

\section{Cómo llevar una minifalda con estilo}

Fonte: Abc Desvilla (2017)

Nesta sentença o verbo llevar remete a uma análise semântica de significado estrito da palavra, primeiro no sentido gramatical do verbo: não se trata do movimento de transportar de um lugar ${ }^{6}$ a outro a peça de roupa minissaia, mas sim, como na língua portuguesa, poderia ser interpretado como "usar", de estilo, de moda; a minissaia, então, no contexto da frase é única e

${ }^{5}$ Disponível em: https://sevilla.abc.es/estilo/bulevarsur/noticias/moda/minifalda-estilo/. Acesso em: 20 jul. 2020.

${ }^{6}$ Como aponta a primeira definição do Gran Diccionario de la Lengua Española Larousse: Tomar una persona, una cosa consigo y hacerla llegar a un destino. 
exclusivamente vista como uma vestimenta. Ainda utilizando as categorias apresentadas inicialmente por Lakoff e Johnson (1980), destaca-se aqui metáforas a partir da categoria semântica estruturada, onde um elemento é compreendido em função de outro (SILVA, 2018), o verbo "llevar" no sentido de vestir que é percebido pelo acompanhamento do substantivo "minifalda".

Percebe-se, então, que o jogo metafórico presente neste enunciado ultrapassa o nível da interpretação de cunho extremamente linguístico e, consequentemente, exige do interlocutor conhecimentos para além disso. Além disso, ressalta-se que, no sentido mais amplo da sentença, é possível imaginar os diversos tipos de estilos de usar minissaia, associando à personalidade da pessoa, logo, o verbo llevar também possui, no seu cunho semântico, os sentidos de "vestir" e "utilizar".

De forma menos expansiva, mas não menos usual, a manchete acima exposta propõe uma troca com o interlocutor no que diz respeito não ao simples uso de uma peça de roupa para cobrir o corpo ou se proteger do frio, por exemplo; mas sim, corrobora com elementos comportamentais que, usados na comunicação verbal, tangenciam linguisticamente o uso de llevar para com usar/vestir/utilizar. Nesse caso, além do cunho cultural exposto nas Manchetes 1 e 2, a Manchete 3 também aponta para o viés de gênero e comportamento aliados à culturalidade que envolvem a língua espanhola: nesse caso, destaca-se frente à temática a vestimenta minissaia como de uso feminino.

A temática da próxima manchete aqui apresentada, Figura 4, diz respeito ao mundo do futebol. Publicada em julho de 2014, o conteúdo completo da matéria jornalística diz respeito ao treinador da equipe de futebol Barcelona e o uso de óculos de sol durante o treinamento dos jogadores:

Figura 4 - Manchete 4

\section{POR QUE LUIS ENRIQUE LLEVA GAFAS DE SOL EN LOS ENTRENAMIENTOS?}

Fonte: Yo Quiero Ser Futbolista (2014) ${ }^{7}$

No enunciado exposto, o verbo llevar é empregado no sentido de usar, não só no sentido de carregar um objeto, mas sim, no sentido de portar para suprir uma necessidade físiológica.

7 Disponível em: http://www.yoquieroserfutbolista.com/por-que-luis-enrique-lleva-gafas-de-sol-en-losentrenamientos/. Acesso em: 15 jul. 2019. 
Tal situação de uso está em harmonia com um dos verbetes do dicionário Larousse: "llevar consigo. 1. Hacerse acompañar por una o varias personas: cada vez que viaja, se lleva consigo a toda la familia. 2. Ser una cosa consecuencia de otra: el matrimonio lleva consigo una serie de responsabilidades". Tais significados e sentidos propostos pelo verbete apontam que o verbo usado pode ser empregado no sentido llevar consigo.

Ao indicar que Luis Enrique lleva gafas, a manchete possibilita inúmeras interpretações ou apreensões de sentidos referente ao sujeito Luis Enrique, remetendo a razões de uso por prescrição médica, ao estilo de uso e até mesmo à personalidade revelada ao escolher o tipo de óculos de sol. Tal impressão confirma-se junto à interrogação colocada na formação sintática da sentença usada como manchete.

Da mesma forma que a manchete anterior, a penúltima manchete aqui apresentada, Figura 5, também tem como temática, embora não tão diretamente, o futebol:

Figura 5 - Manchete 5

\section{La hermana de Cristiano Ronaldo lleva dos años sin pagar la comunidad}

Fonte: Abc Gente \& Estilo (2017) ${ }^{8}$

No enunciado acima, o emprego do verbo llevar revela uma informação comprometedora acerca da irmã do jogador Cristiano Ronaldo, uma vez que remete à sonegação de impostos. Ao proferir o nome do jogador, o locutor faz uma ponte com o interlocutor, para que este compreenda que a irmão do jogador passa por um processo de corrupção. Nesse caso, compreende-se a partir da manchete que dois anos é o tempo de inadimplência para com os órgãos fiscais. Portanto, a expressão lleva dos años poderia ser traduzida na Língua Portuguesa por "faz dois anos que não paga".

Este exemplo pode ser observado no verbete 15 do dicionário consultado: "Haber pasado una persona un tiempo en una situación o lugar lleva seis años en la empresa; llevo horas esperándote". Nesse caso, o verbo llevar é utilizado com o sentido de tempo. Lakoff e Johnson (1980) nos remetem a uma metáfora cronológica e orientacional que indica tempo e espaço, indicando sentidos de tempo decorrido de uma pessoa ou algo haver passado por um determinado tempo em uma situação ou lugar. Ainda, a referida Manchete possui como

8 Disponível em: https:/www.abc.es/estilo/gente/abci-hermana-cristiano-ronaldo-lleva-anos-sin-pagarcomunidad-201703231711_noticia.html. Acesso em: 15 jul. 2019. 
metáfora a construção de uma imagem que ultrapassa tal prerrogativa: o "passar do tempo" não pode ser conduzido por uma pessoa, já que se trata de algo ligado à natureza do planeta Terra.

Além disso, por um olhar mais amplo, percebe-se a ligação entre a temática futebolística - que envolve muito dinheiro -, um jogador de renome internacional - o português Cristiano Ronaldo -; e uma relação familiar - a irmã do jogador da seleção de Portugal: a mídia utiliza essa conexão, ou seja, os sentidos que ela pode trazer, para chamar a atenção do seu interlocutor.

A Figura 6, última manchete analisada, ao contrário das anteriores, tem como uso o verbo llevar para descrever um estado anímico:

Figura 6 - Manchete 6

NOTICIAS

\section{Se burlan de él por ver joyas siendo barrendero... Se lleva una sorpresa}

Un barrendero miraba joyas cuando un usuario de Twitter lo fotografió y se burló de él en la red social... esto pasó después

Fonte: Am Noticias (2016)

Na Língua Portuguesa, em um processo de tradução, poderia ser empregado o verbo "ter" (teve uma surpresa) no lugar do verbo llevar, uma vez que seu emprego está indicando que alguém foi acometido de um sentimento de surpresa: o verbo llevar descreve o sentimento de estranhamento diante de um fato inusitado vivenciado pelo sujeito. Nas categorias apresentadas por Lakoff e Johnson (1980), a metáfora estrutural é quando um determinado elemento é compreendido em função de outro (SILVA, 2018): "se lleva una sorpresa" no sentido de sentir, ou estar surpreso.

Destarte, essa manchete aponta uma conexão com o interlocutor a partir do uso de signos de pontuação - as reticências - como um aporte não só linguístico, mas também que conectam com a curiosidade do leitor: o verbo, então, assume sentidos que diferenciam-se do modo usual, deixando a comunicabilidade entre manchete e leitor em um nível interpretativo diferenciado e leva à curiosidade. Com relação ao nível metafórico, a Manchete 6 apresenta, de forma sutil, uma metáfora estrutural: llevar, nesse caso, remete ao sentido de "ganhar".

9 Disponível em: https://www.am.com.mx/noticias/Se-burlan-de-el-por-ver-joyas-siendo-barrendero...-Se-llevauna-sorpresa-20161206-0065.html. Acesso em: 15 jul. 2019. 


\section{Considerações finais}

Ao observarmos os possíveis sentidos das manchetes analisadas, percebe-se que o verbo llevar carrega interpretações que ultrapassam um conceito unívoco. Embora haja 37 entradas no dicionário Larousse, percebeu-se que no breve e, mesmo pequeno, corpus analisado, o uso do verbo em destaque coloca-se de forma polissêmica e metafórica de acordo com cada situação e as três Categorias Semânticas: estruturais, orientacionais e ontológicas, apresentadas por Lakoff e Johnson (1980), e as situações de cunho ideológico, cultural e situacional. Ou seja, o caráter situacional da linguagem é parte fundamental do verbo llevar e, sempre que o verbo for utilizado, poderão haver novos contextos que proporcionarão novos significados.

É válido ressaltar que as manchetes aqui expostas apresentam, na sua maioria, os sentidos de "usar" e "vestir". Todavia, nas mais diversas situações de uso, não podemos restringir llevar a apenas essas interpretações: é o jogo de locutor e interlocutor que dá forma e sentido a outras possibilidades desse verbo.

Como afirma Moura (2006), a palavra isolada é estéril, mas contextualizada adquire um volume interpretativo e necessário, revelando uma infinita possibilidade polissêmica. Portanto, o contexto é de fundamental relevância para apontar o sentido e para que a sentença seja interpretável. A palavra tem seu significado por si só, porém é no contexto mais amplo do sentido que nos embasamos nestas análises do verbo llevar, com uma análise da semântica argumentativa, observando, contrastando e relacionando as teorias mencionadas neste trabalho em cada caso que as ocorrências do sentido nos remetem.

As metáforas que o verbo llevar apontam neste trabalho vão ao encontro dos pressupostos teóricos mencionados anteriormente: nas palavras de Lakoff e Johnson (1980), e Moura (2006, p. 58), é o "conhecimento compartilhado entre os interlocutores" que se permite fazer uma abstração do verbo llevar além de um sentido unívoco.

Com a breve análise aqui proposta, a partir do uso real do verbo em manchetes de sites da internet, entre os anos de 2013 a 2017, conclui-se que os estudos semânticos contribuem e ampliam nossa interpretação em relação às frases empregadas com o verbo llevar. Dependendo do contexto que o verbo analisado for empregado, ele poderá indicar inúmeras relações de sentido, intencionadas pelo autor ou tanto quanto interpretadas pelo interlocutor. 


\section{REFERÊNCIAS}

ABC DESVILLA. Cómo llevar una minifalda con estilo. 2017. Disponível em:

https://sevilla.abc.es/estilo/bulevarsur/noticias/moda/minifalda-estilo/. Acesso em: 20 jul. 2020.

ABC EL RECREO. El hombre que lleva 46 años sin afeitarse el bigote. 2016. Disponível em: https://www.abc.es/recreo/abci-hombre-lleva-46-anos-sin-afeitarse-bigote201608191107_noticia.html. Acesso em: 20 jul. 2020.

ABC GENTE \& ESTILO. La hermana de Cristiano Ronaldo lleva dos años sin pagar la comunidad. 2017. Disponível em: https://www.abc.es/estilo/gente/abci-hermana-cristianoronaldo-lleva-anos-sin-pagar-comunidad-201703231711_noticia.html. Acesso em: 15 jul. 2019.

ABRAHÃO, V. B. B. A metonímia em London London, conto de Caio Fernando Abreu. Revista do SELL, Universidade Federal do Triângulo Mineiro, v.1, n. 1, p.07, 2008. file://C:/Users/ALEXAN 1/AppData/Local/Temp/11-54-1-PB.pdf. Acesso em: 23 jan. 2019.

AM NOTICIAS. Se burlan de él por ver joyas siendo barrendero... Se lleva una sorpresa. 2016. Disponível em: https://www.am.com.mx/noticias/Se-burlan-de-el-por-ver-joyas-siendobarrendero...-Se-lleva-una-sorpresa-20161206-0065.html. Acesso em: 15 jul. 2019.

BARROS, E. M. Nova gramática da língua portuguesa. São Paulo: Atlas, 1985.

BASSO, R. M. Semântica. Florianópolis: LLV/CCE/UFSC, 2009.

BERNATCOLL. España lleva bigote y conduce un 600. Catalunya lleva minifalda y se siente bien. 2013. Disponível em: https://fcbarcelonaroom.wordpress.com/2013/12/12/espanalleva-bigote-y-conduce-un-600-catalunya-lleva-minifalda-y-se-siente-bien/. Acesso em: 20 jul. 2020.

CACCIARI, C. Why do we speak metaphorically? In: GIBBS, R. Figurative language and thought. Reino Unido: Oxford University Press, 1998.

CÂMARA JÚNIOR, J. M. Dicionário de filologia e gramática: referente à língua portuguesa. 3. ed. São Paulo: J. Ozon, 1968.

CARVALHO, S. N. A metáfora conceitual: uma visão cognitivista. Disponível em: http://www.filologia.org.br/viicnlf/anais/caderno12-04.html. Acesso em: 19 jun. 2019.

LAKOFF, G.; JOHNSON, M. Metáforas da vida cotidiana. Coordenação de tradução: Mara Sophia Zanotto. São Paulo: Mercado das Letras, 2002.

LAKOFF, G.; JOHNSON, M. Metaphors we live by. Chicago/London: The University of Chicago Press, 1980. p. 3-34.

MOISÉS, M. Dicionário de termos literários. 12. ed. rev. e ampl. São Paulo: Cultrix, 2004. MOURA, H. M. M. Polissemia e indeterminação semântica. Apresentação. DELTA, São Paulo, v. 18, n. esp., p. X-XVI, 2002. 
MOURA, H. M. M. Significação e contexto: uma introdução a questões de semântica e pragmática. 3. ed. Florianópolis: Insular, 2006.

MOURA, H. M. M. Substantivos contáveis e incontáveis: uma porta de entrada para a semântica. In: GONÇALVES, A.; GÓIS, M. (org.). Ciências da linguagem: o fazer científico. 1. ed. Campinas: Mercado de Letras, 2014. v. 2, p. 33-66.

SILVA, M. As metáforas cognitivas estruturais definidoras do conceito de linguagem e a sua consequência na construção do ponto de vista em que o objeto-linguagem será construído. Confluência, Rio de Janeiro, n. 54, p. 113-138, jul. 2018. ISSN 2317-4153. Disponível em: http://llp.bibliopolis.info/confluencia/rc/index.php/rc/article/view/249. Acesso em: 12 set. 2019.

ULLMANN, S. Semântica: uma introdução à ciência do significado. Trad. J. A. Osório Mateus. Lisboa: Fundação Calouste Gulbenkian, 1970.

YO QUIERO SER FUTBOLISTA. Por Que Luis Enrique Lleva Gafas De Sol En Los Entrenamientos? 2014. Disponível em: http://www.yoquieroserfutbolista.com/por-que-luisenrique-lleva-gafas-de-sol-en-los-entrenamientos/. Acesso em: 15 jul. 2019.

\section{Como referenciar este artigo:}

BONK MASSAROLLO, A. M. O jogo semântico do verbo llevar: uma análise de manchetes de sites em língua espanhola. Rev. EntreLínguas, Araraquara, v. 6, n. 2, p. 307-322, jul./dez., 2020. e-ISSN: 2447-3529. DOI: https://doi.org/10.29051/el.v6i2.13306

Submetido em: 10/02/2020

Revisões requeridas: $25 / 04 / 2020$

Aprovado em: 22/06/2020

Publicado em: 30/09/2020 